NBER WORKING PAPER SERIES

\title{
EFFICIENCY IN FAMILY BARGAINING: LIVING ARRANGEMENTS AND CAREGIVING DECISIONS OF ADULT CHILDREN AND DISABLED ELDERLY PARENTS
}

\author{
Liliana E. Pezzin \\ Robert A. Pollak \\ Barbara S. Schone \\ Working Paper 12358 \\ http://www.nber.org/papers/w12358
NATIONAL BUREAU OF ECONOMIC RESEARCH
1050 Massachusetts Avenue
Cambridge, MA 02138
July 2006

Pezzin: Medical College of Wisconsin, Milwaukee, WI (lpezzin@mcw.edu). Pollak: Department of Economics and Olin School, Washington University; St. Louis, MO and NBER. (pollak@wustl.edu). Schone: Agency for Healthcare Research and Quality; Rockville, MD (bschone@ahrq.gov). An earlier version of much of the material in this paper was included in "Long-Term Care and Family Decision Making: Coresidence and Efficiency." We are grateful to Shelly Lundberg and Jon Skinner for helpful comments and to NIH grant R01 AG24049-01 for financial support. Pollak is grateful to the John D. and Catherine T. MacArthur Foundation for their support. Earlier versions of this material were presented at Washington University in St. Louis, the University of Pennsylvania, the NBER Cohort Studies group, the University of Kansas, the 2003 ASSA meetings in Washington, DC, the 2003 ESPE meetings in New York, the University of Michigan, the University of Victoria, the University of British Columbia, Carleton University, the University of Colorado, the University of California at Riverside, Williams College, and the 2006 CESifo Area Conference on Employment and Social Protection. The views in this paper are the authors'. No official endorsement by the Agency for Healthcare Research and Quality of the Department of Health and Human Services is intended or should be inferred.The views expressed herein are those of the author(s) and do not necessarily reflect the views of the National Bureau of Economic Research.

(C2006 by Liliana E. Pezzin, Robert A. Pollak and Barbara S. Schone. All rights reserved. Short sections of text, not to exceed two paragraphs, may be quoted without explicit permission provided that full credit, including $(\mathrm{c}$ notice, is given to the source. 
Efficiency in Family Bargaining: Living Arrangements and Caregiving Decisions of Adult Children and Disabled Elderly Parents

Liliana E. Pezzin, Robert A. Pollak and Barbara S. Schone

NBER Working Paper No. 12358

July 2006

JEL No. D1, J1, J2

\begin{abstract}
$\underline{\text { ABSTRACT }}$
In this paper, we use a two-stage bargaining model to analyze the living arrangement of a disabled elderly parent and the assistance provided to the parent by her adult children. The first stage determines the living arrangement: the parent can live in a nursing home, live alone in the community, or live with any child who has invited coresidence. The second stage determines the assistance provided by each child in the family. Working by backward induction, we first calculate the level of assistance that each child would provide to the parent in each possible living arrangement. Using these calculations, we then analyze the living arrangement that would emerge from the first stage game. A key assumption of our model is that family members cannot or will not make binding agreements at the first stage regarding transfers at the second stage. Because coresidence is likely to reduce the bargaining power of the coresident child relative to her siblings, coresidence may fail to emerge as the equilibrium living arrangement even when it is Pareto efficient. That is, the outcome of the two-stage game need not be Pareto efficient.
\end{abstract}

Liliana E. Pezzin

Medical College of Wisconsin

Health Policy Institute, PCOR

Department of Medicine

8701 Watertown Plank Road

Milwaukee, WI 53226

lpezzin@mcw.edu

Robert A. Pollak

Faculty of Arts and Sciences and

John M. Olin School of Business

Campus Box 1133

Washington University

1 Brookings Drive

St. Louis, MO 63130-4899

and NBER

pollak@wustl.edu
Barbara Schone

Agency for Healthcare Research and Quality

540 Gaither Road

Rockville, MD 20850

bschone@ahrq.gov 


\section{Introduction}

Families have long been a mainstay of care for the disabled elderly. In the United States nearly two-thirds of the 5.5 million elderly with chronic disabilities rely, often exclusively, on family members for help with basic activities of daily living (Spillman and Pezzin 2000). Coresidence is an important mode of support that adult children provide for their elderly parents. Although evidence suggests a secular increase in living alone among the elderly (Kotlikoff and Morris 1990), coresidence of disabled elderly parents with their adult children remains fairly common in the United States (Crimmins and Ingegneri 1990; Davis et al. 1997); in 2003 nearly one-fifth of all family households with a member 65 or older contained at least one of the householder's children aged 18 or older (U.S. Census Bureau). Coresidence of elderly parents with adult children is even more prevalent in other parts of the world. In Europe, over one-quarter (26\%) of all individuals 60 or older live with a child, with figures ranging from $43 \%$ in Spain to $4.1 \%$ in Denmark (United Nations 2005). Coresidence rates in Africa, Asia, and Latin America range from two-thirds to threequarters (United Nations 2005).

Coresidence has been linked to both the well-being and health of the elderly. For example, disabled elderly persons who coreside with adult children are less likely than their non-coresiding counterparts to make a transition into a nursing home (Garber and MaCurdy 1990; Kemper and Pezzin 1996; Dostie and Leger 2003). Moon (1983) provides some evidence that coresidence promotes the health of the disabled elderly: she finds that those cared for in the home of a family member have better health outcomes than those in similar 
health who were cared for in an institution.

Coresidence may also benefit the child. Household public goods can be jointly consumed or produced, and economies of scale and other efficiency gains in consumption and production make coresidence less costly than providing equivalent services without coresidence. For example, by sharing a household, adult children may lower the time cost of providing care since travel costs can be avoided. Coresidence, however, reduces privacy for the adult child and, depending of the alternative living arrangement, may also reduce privacy for the elderly parent.

The assistance provided to disabled family members is often the product of numerous individual and joint decisions by family members with different preferences facing different constraints. Family members not only make caregiving decisions on behalf of disabled family members but often provide hands-on care themselves and share the financial consequences of caregiving decisions. Moreover, the preferences of the disabled elderly may differ from those of their spouses and their adult children, and the preferences of one child may differ from those of another. Differences may arise about the type of care desired for disabled parents and the setting in which they receive it. For example, children may want a parent to enter a nursing home, while the parent prefers to live independently; or, a brother may want his sister to care for their mother while the sister wants her brother or his wife to be the primary caregiver. The possibility of conflict regarding caregiving and the roles of different family members in providing care suggest that family members may have incentives to behave strategically.

In this paper we develop a model of family caregiving that captures important 
features of the complex interactions between elderly parents and adult children and among the children. We restrict our attention to the unpartnered elderly, a group of particular policy interest because they are far more likely to be institutionalized (Freedman 1996) and are also more likely to receive care from their children than are their married counterparts (Dwyer and Coward 1991). ${ }^{1}$

We propose and analyze a two-stage game with three players: a disabled parent and two adult children. The first stage determines the living arrangements and the second intrafamily transfers. First-stage decisions affect second-stage bargaining power, but family members cannot or will not make binding commitments regarding their future behavior. We show that even if the second stage is conditionally efficient (i.e., efficient given the living arrangements determined in the first stage), the equilibrium of the two-stage game may be inefficient.

Long-term care for the disabled elderly has sparked a growing literature. The economics literature, surveyed in Norton (2000), focuses on the supply and demand for nursing home care and on long-term care insurance, but pays little attention to the family. Early studies that discuss the role of the family concentrate primarily on support from children to parents in the form of shared housing, analyzing the determinants of living arrangements (Börsch-Supan, 1989; Börsch-Supan, et al., 1989; Ellwood and Kane, 1990; Kotlikoff and Morris, 1990; Börsch-Supan, et al., 1992; Börsch-Supan, McFadden and Schnabel, 1993).

${ }^{1}$ We analyze the caregiving role of spouses in Pezzin, Pollak, and Schone (2005b). 
The first generation of research on families' care arrangements relied on Becker's model of the family (Wolf and Soldo, 1994; Ettner, 1995 and 1996; Kemper and Pezzin, 1996). More recent work has used game-theoretic bargaining models to examine family care arrangements. Two examples will suffice. Pezzin and Schone (1999a, 2002a) specify and analyze a model of living arrangements, informal caregiving, labor force participation, and cash transfers. Their game involves two players, an elderly parent and an adult daughter, each with a utility function defined over a vector of private goods, leisure (for the daughter), and a public good, representing the parent's physical health. Conditional on the parent's disability, the production of the parent's physical health requires that the parent receive some form of care, whether formal (i.e., paid) or informal (i.e., unpaid). Parent and daughter make decisions that determine the levels of private consumption, leisure, cash transfers from the daughter to the parent, the combination of formal and informal care used to produce the parent's physical health or well-being, and the living arrangement (either separate or coresidence). As in the separate spheres model of Lundberg and Pollak (1993), Pezzin and Schone assume that intrahousehold allocation is determined as the solution to a cooperative Nash bargaining game in which the threat point is the Cournot-Nash equilibrium of a noncooperative game.

Heidemann and Stern (1999) and Engers and Stern (2002) develop a game theoretic model of family bargaining designed to motivate a structural empirical model of family long-term care decisions. In particular, they focus on determining whether the parent enters a nursing home, lives independently with no care provided by her children, or, if the parent does receive care from her children, which child becomes the primary caregiver. In their 
formulation, each adult child decides independently whether to attend a meeting in which living and care arrangements for the disabled parent are determined. Both voluntary and compulsory participation versions are analyzed and estimated, with results favoring the voluntary model. The children who participate reach a binding agreement while the nonparticipating children are excluded from family decision making and bear no responsibility for caring for the parent. For each child, the decision of whether to attend the meeting depends on the value she places on participating in the decision, the side payments that she anticipates, and the effect that she anticipates her presence at the meeting would have on the family's decision.

Much of the research examining family caregiving has focused on the parent-child dyad. Although most studies have included variables summarizing the characteristics of the remaining family network (Kotlikoff and Morris 1990; Pezzin, Pollak and Schone 2005c; Pezzin and Schone 1999b and 2002b; Stern 1993 and 1995), little work has analyzed interactions among the adult children. Papers that analyze caregiving with interactions of two or more children include Engers and Stern (2002), Checkovich and Stern (2002), Pezzin and Schone (2001), and Pezzin, Pollak, and Schone (2005a).

To analyze interactions among adult children, we build on research that has modeled intrahousehold allocation within a game theoretic framework (Manser and Brown 1980; McElroy and Horney 1981; Lundberg and Pollak 1993, 1994, and 2003). Game theoretic models are especially suitable for analyzing intergenerational living and transfer arrangements because they recognize the divergent and often conflicting interests of family members and specify a process for translating these divergent interests into outcomes. In 
the next three sections we analyze various three person games involving a disabled elderly parent and two adult children. We examine living arrangements, interhousehold transfers, and intrahousehold transfers. In section 2 we describe the two-stage caregiving game. Like all dynamic games, our two-stage sequential game is solved by backward induction. In section 3 we analyze the second-stage game. We show that, for plausible specifications, the equilibrium of the second stage game is likely to be Pareto efficient conditional on the living arrangement when the parent lives on her own in the community, or in a nursing home, and may be Pareto efficient when she lives with one of her children. In section 4 we analyze the first stage game which determines the living arrangement. We show that, even if the equilibrium of the second stage game is conditionally efficient, the equilibrium of the full game need not be Pareto efficient. Section 5 is a brief conclusion.

\section{A caregiving game with two children}

We consider four possible living arrangements for the parent: living in a nursing home $\left(\mathrm{A}^{\mathrm{n}}\right)$, living on her own in the community $\left(\mathrm{A}^{0}\right)$, living with child $1\left(\mathrm{~A}^{1}\right)$, and living with child $2\left(\mathrm{~A}^{2}\right)$. The parent's utility in each of these living arrangements depends on the living arrangement itself and on her consumption of a private consumption good (C). We use the superscripts $\{\mathrm{n}, \mathrm{o}, 1,2\}$ to indicate the living arrangement and the subscripts $\{\mathrm{p}, 1$, 2 \} to indicate family members. Thus, $\mathrm{C}_{2}{ }_{2}$ denotes private consumption by child 2 when the parent lives alone, and $\mathrm{C}^{2}{ }_{1}$ denotes consumption by child 1 when the parent lives with child 2. We assume that children care about their own private consumption and about the parent's private consumption. We also assume that the children care about the parent's living 
arrangement, which affects the parent's well being and the child's privacy.

Economists' usual assumption about preferences -- what Becker (1981) calls

"altruistic" preferences -- implies that the children defer to the disabled parent's preferences

over her own consumption and, in some cases, over her living arrangements as well. For

example, Becker's children would defer to the parent's preference between living in a

nursing home and living on her own in the community. We regard Becker's altruistic

preferences as an implausible special case even when the parent is not cognitively impaired

(e.g., with Alzheimer's). We also dislike Becker's terminology, which forces us to say that

a child who rejects a disabled parent's preference for living alone (e.g., because the child

believes that the parent cannot safely live alone) is not altruistic. ${ }^{2}$ In this paper we treat

consumption as one dimensional, avoiding the issue of merit goods except in regard to

living arrangements. Pezzin and Schone (1999a; 2002a) analyze a model with two goods,

one of which is a merit good.

We model family interactions as a two-stage game in which both stages may contain substages. The first stage is noncooperative and determines the living arrangement. The second stage determines consumption. We assume that family members cannot or will not make binding agreements at the first stage regarding assistance or allocations at the second

${ }^{2}$ In the introduction to the 1991 edition of his Treatise on the Family, Becker concedes that "The most unsatisfactory aspect of my discussion...[in the 1981 edition is]...the failure to combine the discussion of 'merit goods' and altruism" (p. 10). Just as merit goods can motivate paternalistic governments to provide tied transfers (e.g., food stamps), merit goods can motivate paternalistic family donors, when they have the ability, to provide tied rather than untied transfers. Pollak (1988) proposed a model in which family members have paternalistic preferences. In place of Becker's term, "altruistic" preferences, Pollak (2003) argues that "deferential" preferences is more descriptive. 
stage. Hence, the assistance that a child provides at the second stage, although it may be predictable at the first stage, is determined at the second stage.

Although we cannot directly observe the impact of not having binding agreements on decisions made at the second stage, the lack of binding agreements may partially explain some empirical regularities associated with caregiving. For example, the concentration of caregiving by coresident caregivers and the relatively small amount of assistance provided by the noncoresident caregiver may reflect the fact that, once the parent begins to live with one child, the other children reduce the care they provide confident that the coresident child will make up the difference.

Suppose, for example, that the first stage begins with the children deciding, separately and simultaneously, whether or not to invite the parent to coreside and ends with the parent choosing among the feasible living arrangements: she can move into a nursing home, live on her own, or accept the invitation of any child who has invited her to coreside. At the second stage, taking as given the living arrangement determined at the first stage, the children and the parent make decisions that determine resource allocation under that living arrangement. We can model the second stage as a noncooperative game or as a cooperative game; alternatively, we can finesse some but not all of the difficulties of modeling the second-stage game by postulating an "allocation rule." We define an allocation rule as a specification of each family member's second-stage behavior as a function of the living arrangement, which is determined in the first stage, of the economic and demographic characteristics of all players, and of any relevant policy parameters (e.g., voucher programs, tax subsidies for caregivers, allowances for dependent care). 
We have adopted and adapted the idea of an allocation rule from Chiappori (1988, 1992) who proposed a "sharing rule." In the context of allocation between spouses within marriage, Chiappori postulates a single-valued, Pareto-efficient sharing rule which determines each spouse's utility. Chiappori postulates the sharing rule directly, and does not attempt to derive it from an underlying model of bargaining. Unlike Chiappori's sharing rule, our allocation rule describes the allocation of goods rather than utility and, again unlike Chiappori’s sharing rule, our allocation rule need not be single-valued or Pareto efficient. By beginning with the allocation rule, we avoid not only the need to analyze the secondstage game but also the need to specify it, or even to specify whether it is cooperative or noncooperative.

A priori, it is unclear whether family decision making should be modeled as a cooperative or a noncooperative game. Shubik (1989, p. 103) asserts that noncooperative game theory "is generally not so useful to describe complex, loosely structured social interaction." Family bargaining -- whether between spouses within marriage, between an adult child and a disabled parent, or among adult children -- exemplifies such interactions. But the usefulness of cooperative game theory is also problematic. First, although cooperative game theory allows us to proceed without specifying the "rules of the game" -the strategies available to each player, or in extensive form, the sequence of moves and the information available to each player at each move - noncooperative game theory teaches that the rules of the game are often crucial determinants of the outcome. Thus, by modeling interactions as a cooperative game we necessarily disregard the strategic factors which may determine the outcome. Second, the efficiency of social arrangements and practices is a 
central concern of economics and of public policy, yet cooperative bargaining models assume that outcomes are Pareto efficient. Hence, cooperative bargaining models are incapable of investigating the conditions that make it possible to achieve and sustain efficient outcomes because cooperative models refuse to recognize the possibility of inefficiency. Because complex, loosely structured social interactions are very difficult to model, we regard the choice between modeling family interactions as a noncooperative or a cooperative game not a matter of principle but of research strategy. In the following section we consider alternative specifications of the second stage game.

\section{The second stage game: child to parent transfers}

For each of the four possible living arrangements, we consider several formulations of the second state game which determines transfers from children to the parent. We assume that each child's utility is increasing in the parent's consumption and in her own consumption, but is independent of her sibling's consumption. Hence, a child's utility increases if the sibling's contribution to the parent increases. ${ }^{3}$

$A^{o}$. Suppose that the parent lives on her own in the community.

When the parent lives independent in the community or in a nursing home, we assume that the parent accepts whatever transfers the children offer her. Hence, with these

${ }^{3}$ Consider two polar cases: (a) the child responds to the increase in the siblings's contribution by reducing her own contribution by the same amount, thus increasing her own consumption and leaving the parent's consumption unchanged. (b) the child responds by leaving her own contribution to the parent unchanged, thus increasing the parent's consumption and leaving her own consumption unchanged. 
living arrangements, the parent is not a strategic player in the second stage game. ${ }^{4}$ The children may play a one-shot noncooperative game, a repeated cooperative game, or a cooperative game. We consider each of these in turn.

\section{$A^{o}$.i. A noncooperative, one-shot, voluntary contribution game.}

The one-shot Cournot-Nash game is familiar but not very plausible. Using "reaction functions" which show each child's best response to the transfers made by the other, we can calculate the equilibrium. (Figure 1). When public good provision is a simultaneous move one-shot game, the public good will be underprovided. More specifically, if both children make positive contributions to the family public good, then the equilibrium is Pareto inefficient: there exist strictly greater contribution levels that both children would prefer to the Cournot-Nash equilibrium.

This underprovision result does not hold if only one child makes positive contributions in the Cournot-Nash equilibrium. In the one contributing child case, just as in the one-child case, provision is Pareto efficient.

\section{$A^{o}$.ii. A noncooperative, repeated, voluntary contribution game.}

Now suppose the children play a repeated voluntary contribution game. More specifically, suppose that at the beginning of every period each child has the opportunity to make transfers to the parent. To simplify the analysis, suppose that neither the parent nor

\footnotetext{
${ }^{4}$ When the parent coresides with one of the children, we discuss cases in which the parent is a strategic player.
} 
the children can carry over resources from one period to another, so that the stage games played in successive periods are identical. Hence, the stage games are related only because the children can punish each other for misbehavior by reducing their own contributions to the public good.

If the children are sufficiently patient, then the folk theorem asserts that any feasible, individually rational allocation is a subgame perfect equilibrium of the repeated game. Hence, the repeated game has a very large set of subgame perfect equilibria some of which are Pareto efficient, but many of which are not. Unless we introduce additional assumptions about how family members play the game, we cannot narrow down the set of subgame perfect equilibria or assign probabilities to them. A cogent objection to modeling children's transfers to a disabled elderly parent as an infinitely repeated game is the assumption that the game will continue indefinitely. Because the game will eventually stop, end game considerations may affect behavior from the outset. The theoretical argument that games with known end points unravel is strong, but empirical evidence suggests that unraveling need not occur. ${ }^{5}$ Stochastic termination is more plausible, perhaps because of the death of the parent or one of the children or a dramatic change in the parent's health status (e.g., a stroke requiring hospitalization, making continued independence infeasible). The nonstationarity of the stochastic came complicates the analysis.

${ }^{5}$ The "centipede game" is the standard example of an experimental game in which unraveling does not occur. See Kreps (1990) and McKelvey and Palfrey (1992). 


\section{$A^{o}$.iii. A cooperative game.}

Now suppose, as Shubik would have us assume in analyzing a "complex, loosely structured social interaction," that the second-stage game is cooperative. We can conclude immediately that, conditional on the living arrangement, the second stage equilibrium is Pareto efficient. Unlike noncooperative games, cooperative games make no mention of strategies or moves, but instead require a specification of the payoffs attainable by each coalition and a solution concept. We discuss two solution concepts: the core and the Nash bargaining solution.

The core is the set of feasible, undominated allocations -- allocations that cannot be improved upon by any coalition. Because a core allocation cannot be improved upon by the coalition of all players, every core allocation is Pareto efficient. A drawback of the core as a solution concept is that it not only fails to predict a unique equilibrium but that the set of equilibria is large. ${ }^{6}$ Without additional assumptions, we cannot reduce the set of equilibria or assign probabilities to the elements of the set. The Nash bargaining solution, the leading solution concept in bargaining models of marriage, selects a particular core outcome as the solution. (Figure 2). Which core allocation it selects depends on the specification of the threat point $\left(\mathrm{T}^{1}, \mathrm{~T}^{2}\right) .^{7}$ The core, despite its prominence in game theory, has received almost

${ }^{6}$ If the players are sufficiently patient, the folk theorem implies that the set of equilibria in the repeated game is much larger than the core.

${ }^{7}$ Bargaining models of marriage have emphasized Nash bargaining and neglected other cooperative bargaining models and solution concepts. For example, although Manser and Brown considered both the Nash and the Kalai-Smorodinsky (1975) bargaining solutions, subsequent work on bargaining in families has virtually ignored Kalai-Smorodinsky. Gugl (2004) provides an interesting exception, considering both the Nash and Kalai-Smorodinsky bargaining solutions. Gugl's work suggests that the difficulty of doing comparative statics with Kalai-Smorodinsky may account for its eclipse by the Nash bargaining solution. 
no attention as a solution concept in the economics of the family, perhaps because it does not yield a unique solution in two-person games, and perhaps because, in games with more than two players, the core may be empty.

$A^{o}$ iv. Pareto efficiency when the parent lives on her own in the community

When the parent lives on her own in the community Pareto efficiency is plausible but not necessary. The Coasian tradition holds that efficient outcomes emerge from bargaining, at least when the number of agents is small, information is symmetric, and transaction costs are negligible. But the Coasian tradition rests on assumption, not on argument. Indeed, a critic might argue that the Coasian tradition amounts to little more than following Shubik's suggestion and assuming that family bargaining is a cooperative game.

$A^{n}$. The parent lives in a nursing home.

The logical structure of the second-stage game when the parent lives in a nursing home is essentially identical to its structure when she lives on her own in the community. As when the parent lives on her own in the community, in the second stage game the children take the parent's living arrangement as given. Not surprisingly, some specifications of the second stage game imply efficient equilibria, other specifications imply inefficient equilibria, and still others imply multiple equilibria, some efficient and some inefficient. As when the parent lives on her own in the community, Pareto efficiency is plausible but not necesssary. Because at this level of abstraction the efficiency of transfers when the parent lives in a nursing home presents no new conceptual issues, we discuss it no further. 
$A^{1}, A^{2}$. The parent resides with a child.

Coresidence increases the strategic asymmetry between the children and weakens the bargaining power of the coresident child. Of course strategic asymmetry is always present. Even when the parent lives independently in the community or in a nursing home, the children may differ in gender, family responsibilities, labor force attachment, and attachment or proximity to the parent. ${ }^{8}$ Like coresidence, many of these differences are endogenous. For definiteness, and without loss of generality, for the remainder of this section in which the parent coresides with a child, we suppose that the parent coresides with child 1 .

We emphasize the strategic asymmetry between the coresident and the noncoresident child because it has implications for the choice of living arrangements in the first stage game. We begin by assuming that the parent is a passive spectator rather than a strategic player. Using the model proposed by Weiss and Willis (1985) in the context of child support following divorce, we examine the implications of coresidence for the noncoresident child's ability to monitor the way transfers are used by the coresident child. We then consider the way in which coresidence and the frequency of contact it implies is likely to affect the coresident child's awareness of the parent's needs or her attachment to the parent. Finally, we allow the parent to be a strategic player, assuming that allocation within the coresident household is the outcome of a cooperative game between the coresident child

${ }^{8}$ Konrad, et al. (2002) argue that older children exploit their first mover advantage by moving away from their parents, leaving younger children to bear a disproportionate share of long-term care responsibilities. 
and the parent.

Weiss and Willis provide a framework for analyzing the effect of coresidence on bargaining power. Their concern is child support following divorce, but the strategic position of the noncoresident child contemplating contributing to the coresident household is similar to that of the noncustodial parent contemplating child support. In Weiss and Willis the child's well-being is a parental public good valued by both parents. Each parent, however, is also concerned with his or her private consumption and unconcerned with the private consumption of the ex-spouse. The noncustodial parent, for definiteness, the divorced father, because he does not coreside with the child, is poorly positioned to monitor his ex-wife's allocation of child support between herself and the child. Weiss and Willis view the inability of the father to monitor the mother's allocation of resources between herself and the child as the crucial feature of the strategic situation. The inability to monitor precludes binding, enforceable agreements between the parents: the father is rationally concerned that if he increases his contribution, his ex-wife will respond by reducing hers.

Weiss and Willis model child support as a one-shot Stackelberg game: the first mover, the father, contributes resources to the mother; the mother then allocates resources between herself and the child. As Weiss and Willis show, the equilibrium allocation is Pareto inefficient: both parents would prefer an allocation in which they both reduced their private consumption and increased their transfers to the child. The Stackelberg game captures the intuition that the child will receive less than the Pareto-efficient level of resources. The Weiss and Willis conclusion is appealing, although asymmetric information, inability to monitor, and the consequent inability to make binding agreements, play no role 
in their formal model.

Neither child support nor long-term care is a one-shot Stackelberg game, but the Weiss and Willis insight about the strategic importance of the inability to monitor applies to both. The analogy between long-term care and the Weiss and Willis Stackleberg model of child support is closest when the parent has a cognitive disability such as severe Alzheimer's that precludes her active participation in the allocation process. Under these circumstances, the coresident child allocates resources between herself and the parent, just as in Weiss and Willis the mother allocates resources between herself and an infant. Replacing the one-shot Stackelberg game by a sequence of Stackelberg games would not alter the analysis. If the noncoresident child is unable to monitor the allocation of resources in the coresident household, then she lacks the information required to know when to "punish" the coresident child. The analysis of both long-term care and child support becomes more complicated if the individual receiving care is an active player rather than a passive recipient of care.

Once coresidence is established, the coresident child may have incentives to maintain it because termination would impose high psychic costs or adversely affect instrumental or affective relationships with other family members. That is, once coresidence becomes the status quo, the coresident child may find termination difficult and costly. We can interpret the coresident child's incentives to continue coresidence in terms of rewards offered for continuing or, equivalently, in terms of punishments threatened for terminating. The noncoresident child, knowing that her sister cannot easily terminate coresidence, realizes that if she reduces her contribution, the coresident child will respond by increasing hers. England and Folbre (2003), describing the predicament of paid care 
workers, write: "these emotional bonds [to those receiving care] put care workers in a vulnerable position. We might call the workers 'prisoners of love'; a kind of emotional 'hostage effect' comes into play" (p. 73). The logic of their argument applies with even greater force to care provided by family members. ${ }^{9}$

We now drop our assumption that the parent is a passive spectator and assume instead that she is an active player. We begin with the one-child case and consider the implications of coresidence for bargaining between the coresident child and the parent. We then return to the two-child case, and consider the implications of coresidence for bargaining between the noncoresident child, the coresident child, and the parent.

Following Pezzin and Schone (1999a, 2002a) we assume that when the parent and the child coreside their interactions are cooperative but when they do not coreside their interactions are noncooperative. We assume that, within the coresident household, control over resources affects allocation. That is, government and family transfers to the coresident child have a different effect than transfers to the parent. More formally, resources controlled by the coresident child and resources controlled by the parent are separate arguments of the coresident household's allocation rule. Empirical work by Hayashi (1995) and by Pezzin and Schone (1997) on allocation within two-generation households finds that resources controlled by the elderly parents have a different effect on household expenditure

$9 \quad$ In a dynamic model, contributions by the noncoresident child might decrease over time while contributions by the coresident child might increase; our static models, however, cannot accommodate this behavior. 
patterns than resources controlled by their coresident adult children. ${ }^{10}$

Government programs that provide direct payments, in-kind services, or tax incentives to households with a disabled elderly member are uniform across households rather than tailored to the allocation rules of particular households. Government transfers, like private transfers, affect allocations in the coresident household through its allocation rule. Hence, government policies that provide resources to disabled elderly parents will have systematically and predictably different effects than policies that provide the same resources to coresident children.

We now return to the two child case. To model the asymmetry between the positions of the noncoresident child and the coresident child, we assume that the second stage game contains two substages: in the first substage, the noncoresident child makes transfers to the coresident child and to the parent; in the second substage, the coresident child and the parent play a cooperative game. For definiteness, think of the coresident household's behavior as determined by a cooperative Nash bargaining game in which the threat point depends on the allocation of transfers between the coresident child and the parent. ${ }^{11}$ Thus, the noncoresident child must decide not only how much to transfer to the

10 In a similar vein, empirical work by Lundberg, Pollak and Wales (1997) on allocation within married couple households finds that resources controlled by husbands have a different effect on household expenditure patterns than resources controlled by wives.

11 We do not assume that the parent and the coresident child play as a "team." The team assumption, like the unitary model, would imply that the parent and the coresident child act as a single player. That is, the coresident household would act as if it had a single preference ordering and a single budget constraint (i.e., as if the parent and the coresident child pooled their resources). If the coresident child and the parent are a team, then the behavior of the coresident household would be independent of how the noncoresident child or the government allocated transfers between the coresident child and the parent. 
coresident household, but also on the allocation of transfers between the coresident child and the parent. ${ }^{12}$ We represent the allocation that emerges from the full second stage game by an allocation rule.

Pareto efficiency is less plausible when the parent coresides with one of the children. Within the coresident household, Pareto efficiency depends on assuming either that the parent is not an active player or, alternatively, that the parent and the coresident child bargain to a Pareto-efficient allocation. Of course Pareto efficiency in the coresident household is guaranteed if the parent and the coresident child play a cooperative game. The difficulty, however, is not within the coresident household but in interactions between the coresident household and the noncoresident child. The situation is similar to that modeled by Weiss and Willis in their analysis of child support by noncustodial (and noncoresident) parents. In the long-term care context, the noncoresident child might be willing to contribute or contribute more to the disabled elderly parent, but refrains from doing so because she is concerned that any contribution she makes would be at least partially offset by a reduction in the contribution of the coresident child. Thus, when the parent coresides with one of her adult children, Pareto efficiency in the second stage game is possible but not as plausible as when the parent lives on her own in the community or in a nursing home.

12 The government may allocate a portion of its transfers to the coresident child rather than the disabled elderly parent, and by doing so may induce a child to invite coresidence. A child cannot use the prospect of such transfers to induce a sibling to offer coresidence unless at least of one the children is willing and able to make a binding commitment. 


\section{The first stage game: living arrangements}

In this section we analyze the first stage game. In section 4a we show that the equilibrium of our two-stage game can be Pareto inefficient even when the second stage game is Pareto efficient conditional on the living arrangement. In section $4 \mathrm{~b}$ we show that the equilibrium may depend on the precise specification of the first-stage game (e.g., when the game is sequential, the equilibrium may depend on which child moves first), and we consider games in which the parent is an active player. Finally, in section 4c we show that the game may have multiple equilibria; more specifically, we consider a game in which all family members move simultaneously and show that 5 of its 12 strategy profiles are equilibria.

We begin by describing the first stage game. Because the parent cares about living arrangements as well as private consumption, she might prefer to live independently with fewer consumption goods than live with child i with more. Suppose that the second-stage game associates with each living arrangement unique consumption values for the parent and the children. We assume that the parent can rank the four possible alternatives $\left\{\left(C^{n}, A^{n}\right)\right.$, $\left.\left(C_{p}^{0}, A^{0}\right),\left(C_{p}^{1}, A^{1}\right),\left(C_{p}^{2}, A^{2}\right)\right\}$ or, if the parent is also concerned with the children's consumption, $\left\{\left(C_{p}^{n}, C_{1}^{n}, C_{2}^{n}, A^{n}\right),\left(C_{p}^{0}, C_{1}^{0}, C_{2}^{0}, A^{0}\right),\left(C_{p}^{1}, C_{1}^{1}, C_{2}^{1}, A^{1}\right),\left(C_{p}^{2}, C_{1}^{2}, C_{2}^{2}\right.\right.$, $\left.\mathrm{A}^{2}\right)$ \}. In either case, these preferences over consumption and living arrangements induce a preference ranking over living arrangements by the parent and by each of the children. These induced preferences play a crucial role in our analysis of the first stage game. Each child's preferences reflect his or her concern for the parent's private consumption as well as 
the implications of each living arrangement for the child's private consumption. ${ }^{13}$

As an initial example, we model the first stage as consisting of simultaneous moves by the siblings, followed by a decision by the parent, who chooses among the living arrangements available to her. Each child has two moves: inviting coresidence (v) or not inviting coresidence $\left(\mathrm{v}^{\prime}\right)$. For each profile of moves (e.g., both invite coresidence; child 1 invites coresidence and child 2 does not, etc.), we assume that the resulting levels of utility are known to each child (e.g., if both invite coresidence, they know that the parent will choose to live with child 1), or, more precisely, they can assign probabilities to each living arrangement.

In the first stage example described above, the parent will choose her preferred living arrangement from the available options determined by the children's invitations. This choice is based on the parent's calculation of the utility levels attainable in each living arrangement. The parent faces at most four alternatives, depending on whether both children invite coresidence, neither child invites coresidence, or one child invites coresidence and the other does not. Two loose ends remain: nonuniqueness in the solution to the second stage game, and nonuniqueness in the parent's choice.

If the allocation rule associates a unique consumption pattern with each living arrangement, then the parent will prefer one to the other or be indifferent between them. We assume that the parent's ranking of living arrangements is an ordering. If the ordering is

\footnotetext{
${ }^{13}$ Problems can arise if the second-stage game associates more than one consumption value with some living arrangement. More specifically, the analysis proceeds with no difficulty provided probabilities are associated with each of the possible consumption outcomes. Without such probabilities, however, the analysis is dead in the water.
} 
strict (i.e., no ties), then we can proceed directly to the analysis of the first stage game. If the ordering is not strict, then the parent will sometimes face situations in which the "best" living arrangement is not unique. Although such ties pose no problem for the parent, they do for the children who must decide at the first stage whether to invite coresidence. Henceforth, we assume that the ordering is strict to avoid the difficulties associated with ties.

A multiplicity of equilibria in the second stage game poses a troubling problem. ${ }^{14}$ The problem arises because the parent cannot choose among living arrangements unless she can assign probabilities to each allocation in the set. If the allocation rule associates probabilities with each allocation in the set, then choosing among living arrangements is like choosing among lottery tickets. In the absence of such probabilities, however, we encounter difficulties modeling parental choice.

Before turning to our examples, we dispose of an expositional complication. We want to treat family members as if they have direct preferences over living arrangements. Provided the parent and the children can predict the transfers that would take place in each possible living arrangement, we can legitimately focus on induced preferences over living arrangements, relying on the fact that each living arrangement is associated with unique levels of private consumption, of care for the parent, and of privacy for the children and for the parent. Hence, instead of carrying forward notation that explicitly recognizes the role of private consumption for the children and for the parent, we work with the induced

14 Multiple equilibria can arise in cooperative second stage games (e.g., when the core is the solution concept) and in noncooperative second stage games (e.g., in repeated games as a consequence of the folk theorem. 
preferences over living arrangements.

\section{4a. Pareto Inefficient Equilibria}

To construct an example of a game with an inefficient equilibrium, we begin by specifying the preferences of each family member. Suppose preferences for the parent's living arrangement (taking account of the transfers that would be made and the implied consumption pattern) are represented by:

\begin{tabular}{|l|c|c|c|}
\hline & Parent's Ranking & Child 1's Ranking & Child 2's Ranking \\
\hline & \multicolumn{3}{|c|}{ Parent lives: } \\
\hline First Choice & with Child 1 & with Child 2 & with Child 1 \\
\hline Second Choice & with Child 2 & independently & independently \\
\hline Third Choice & independently & with Child 1 & with Child 2 \\
\hline Fourth Choice & in nursing home & in nursing home & in nursing home \\
\hline
\end{tabular}

That is, the parent prefers to live with child 1, but would rather live with child 2 than live independently. Each child prefers that the parent coreside with the other child, and each child would prefer that the parent live independently rather than coreside with the parent. The unique equilibrium, indeed, the dominant strategy equilibrium, of any game in which the children have these preferences has the parent living independently. With these preferences, the nursing home living arrangement is an option that the parent would never choose, and one that the children know that she would never choose.

Suppose, however, that each child would invite coresidence if she knew her sister would contribute "enough," and that the sister would rather contribute enough than have the 
parent live independently. ${ }^{15}$ An omniscient and omnipotent social planner could impose a solution on the family that would make everyone -- the parent and both children -- better off by requiring that the parent live with child 1 and requiring child 2 to contribute "enough." But the family cannot achieve this or any other Pareto-efficient solution and is misguided, as if by an invisible hand, to a Pareto inefficient equilibrium. The demonstration of inefficiency depends on comparing a living arrangement and transfer pattern that a social planner might impose with the living arrangement and transfer pattern that would emerge as the equilibrium of a two-stage game. Our argument does not establish nor do we claim that for all configurations of preferences the equilibrium of the two-stage game is inefficient. We have established that for some configurations of preferences the equilibrium is inefficient.

Lundberg and Pollak (2003) describe and analyze a related two-stage game in the context of the "two-earner couple location problem." In Lundberg and Pollak, spouses play a two-stage game in which the first stage determines the location (e.g., whether the couple moves to the husband's preferred location or the wife's preferred location), and the second stage determines allocation within marriage. When the spouses prefer different locations, inefficient outcomes (e.g., inefficient divorces) are possible even when the second stage game is efficient conditional on the location determined in the first stage. An analogous result holds in our long-term care game -- the equilibrium of the two-stage long-term care

15 Anna Rubinchik-Pessach suggests formalizing this by supposing that there are two possible contribution levels, 0 and $\mathrm{T}^{* *}$, and writing down preference profiles corresponding to each of them. Thus, everyone prefers the outcome in which child 2 contributes $\mathrm{T}^{* *}$ and mom lives with child 1 , but that outcome is not an equilibrium of the two-stage game. 
game may be an inefficient living arrangement, even when second stage transfers are efficient conditional on the living arrangement. The crucial features of both the two-earner couple location game and our long-term care game are that first-stage decisions affect future bargaining power and that family members cannot or will not make binding, enforceable agreements.

$4 b$. Outcomes depend on the structure of the first-stage game

To construct an example in which the equilibrium living arrangement depends on the precise specification of the first stage game, we again begin by specifying each family member's preferences.

\begin{tabular}{|l|c|c|c|}
\hline & Parent's Ranking & Child 1's Ranking & Child 2's Ranking \\
\hline & \multicolumn{2}{|c|}{ Parent lives: } \\
\hline First Choice & with Child 1 & with Child 2 & with Child 1 \\
\hline Second Choice & with Child 2 & with Child 1 & with Child 2 \\
\hline Third Choice & independently & independently & independently \\
\hline Fourth Choice & in nursing home & in nursing home & in nursing home \\
\hline
\end{tabular}

That is, the parent prefers to live with child 1 , but would rather live with child 2 than live independently. Each child prefers that the parent coreside with the other child, but each child prefers coresidence with the parent to having the parent live independently. Both children and the parent prefer having the parent live independently rather than in a nursing home. 
Using these preferences, we consider alternative specifications of the first stage game. We first consider three specifications of the noncooperative first-stage game in which the children move before the parent, then three specifications in which the parent moves before the children. Finally, we consider a specification in which the parent and the children move simultaneously.

\section{i. Children move before the parent.}

We consider two sequential games that differ in which child moves first and a simultaneous move game. When Child 1 moves first, she does not invite (v') the parent to coreside; the best response of child 2 is to invite (v) the parent to coreside, and the parent accepts the invitation. When Child 2 moves first, she does not invite the parent to coreside; the best response of child 1 is to invite the parent to coreside, and the parent accepts the invitation. The simultaneous move game has two pure strategy equilibria: (1) Child 1 invites coresidence, and child 2 does not; the parent accepts the invitation of child 1. (2) Child 2 invites coresidence, and child 1 does not; the parent accepts the invitation of child $2^{16}$

These examples demonstrate that the equilibrium of our two-stage game can depend on the precise specification of the game (e.g., which child moves first in the sequential game) and that some specifications of the game (e.g., the game in which the children move simultaneously) can have multiple equilibria. In section 4c we offer an example with a

16 The simultaneous move game also has a mixed strategy equilibrium which we shall not discuss. 
richer set of equilibria.

\section{ii. Parent moves before the children.}

When the parent moves first, she can be a strategic player. Suppose that the parent can commit herself to reject particular invitations, if she should receive them. ${ }^{17}{ }^{18}$ More specifically, the game begins with the parent choosing among three moves.

(i) preemptively reject an invitation from Child 1 (r1)

(ii) preemptively reject an invitation from Child 2 (r2)

(iii) make no preemptive rejection of any invitation (r')

The children then move, either sequentially or simultaneously, as described above. Finally, the parent chooses a living arrangement: she can live independently or in a nursing home or accept any invitation she has received except those she has preemptively rejected.

The analysis of these games is straightforward. The parent begins by committing herself to rejecting an invitation from child 2. The equilibrium of all three games -- the two sequential games and the simultaneous game -- is an invitation from child 1, which the parent accepts. This example shows that the ability of a family member (in this case, the parent) to commit can alter the equilibrium outcome and, in this case, commitment enables the parent to achieve the outcome she prefers.

17 Shelly Lundberg suggests that the parent might achieve the same result by insulting a child's spouse.

18 We assume that the parent cannot commit herself to reject living independently or in a nursing home. If she could commit herself to rejecting one or both of these living arrangements (e.g., by starving herself to death), she might be able to force coresidence. 
4c. Multiple equilibria

iii. The parent and the children move simultaneously.

The simultaneous game has 12 strategy profiles and 5 of these are equilibria. Recall that the disabled parent has 3 possible strategies (r1, r2, r'), and each child has two possible strategies $\left(\mathrm{v}, \mathrm{v}^{\prime}\right)$. The reader can verify that the 5 equilibria are:

(r1, v', v) parent lives with child 2

(r2, v, v') parent lives with child 1

$(\mathrm{r} 2, \mathrm{v}, \mathrm{v})$ parent lives with child 1

$\left(r^{\prime}, v^{\prime}, v\right)$ parent lives with child 2

(r', v, v') parent lives with child 1.

As this example shows, some specifications of the game have a large number of Nash equilibria. $^{19}$

4d. Agency for the parent

As we have already seen, the parent becomes a strategic player in the first-stage game if she has the ability to reject certain invitations. An alternative specification of the first-stage game can increase the parent's bargaining power. Instead of assuming that the children issue invitations which the parent must accept or reject, suppose that the parent issues invitations which the children must accept or reject.

For the configuration of preferences in our first example, the parent derives no

19 If the parent moves first and the children observe her move and then play a simultaneous move game, then all of these Nash equilibria are subgame perfect. 
strategic advantage from issuing invitations: regardless of what invitations she issues, the only equilibrium is living independently in the community. ${ }^{20}$ For the configuration of preferences in our second example, the parent can achieve her preferred outcome (living with child 1) if she can issue invitations. For example, if the rules of the game require her to issue all invitation simultaneously, then she can accomplish her desired outcome by issuing an invitation only to child 1 . If the rules of the game allow sequential invitations, she can accomplish her desired outcome by first inviting child 2 to coreside and, when child 2 rejects her invitation, inviting child 1 to coreside.

\section{Conclusion}

We have used a two-stage bargaining model to analyze the living arrangement of a disabled elderly parent and transfers to the parent from her adult children. The first stage determines the living arrangement, the second child-to-parent transfers. Working by backward induction, we first calculate an allocation rule that specifies the level of transfers that each child would provide to the parent in each living arrangement. We then analyze the living arrangement(s) that emerge as equilibria of the first stage game. Because the living arrangement affects bargaining power in the second stage game, and because family members at the first stage are unwilling or unable to make binding agreements regarding transfers at the second stage, the equilibria of the two-stage game may be Pareto inefficient even if the equilibrium of the second stage subgame is conditionally efficient.

20 The outcome might be different if the parent could commit herself to moving into a nursing home, the worst outcome for her and for the children, unless child 1 would coreside with her. 
A better understanding of the process by which families come to assume the responsibility and share the burden of caring for the disabled elderly is essential for designing and evaluating long-term care policies. As governments increasingly explore policies to address the needs of their growing disabled elderly populations, the possibility that families' long-term care decisions may result in inefficient outcomes suggests an additional role for public policy. Initiatives may be tailored to family living arrangements, for example, by taxing non-coresiding adult children or subsidizing co-residing adult children for both their informal care services and relative loss of bargaining power, in order to promote more efficient outcomes. ${ }^{21}$ While government transfer schedules that are independent of family living arrangements are analytically simpler than schedules that are not, contingent transfer schedules may limit the deadweight loss associated with government efforts to ensure the availability of long-term care. Public long-term care policy will be enhanced by recognizing that the caregiving behavior of family members responds to the incentives created by public programs.

${ }^{21}$ In the United States, examples of such an initiative are state programs under the Home and Community-Based Waivers that either condition eligibility for services on the presence of an "active" family caregiver or provide more, rather than less, hours of paid assistance to elderly persons who coreside with a family caregiver (Centers for Medicare and Medicaid Services 2004). 


\section{References}

Becker, G. S. (1981, 1991) Treatise on the Family, Cambridge: Harvard University Press, 1981.

Börsch-Supan, A. (1989) "Household Dissolution and the Choice of Alternative Living Arrangements Among Elderly Americans" in D. Wise (ed.) The Economics of Aging. Chicago: University of Chicago Press: 119-150.

Börsch-Supan, A., L. Kotlikoff and J. Morris (1989) "The Dynamics of Living Arrangements of the Elderly: Health and Family Support" NBER Working Paper No. 2787.

Börsch-Supan, A., V. Hajivassiliou, L. Kotlikoff and J. Morris (1992) "Health, Children and Elderly Living Arrangements" in D. Wise (ed.) Topics in the Economics of Aging. Chicago: University of Chicago Press:79-103.

Börsch-Supan, A., D. McFadden and R. Schnabel (1993) "Living Arrangements: Health and Wealth Effects" NBER Working paper No.4398.

Centers for Medicare and Medicaid Services (2004)

http://www.cms.hhs.gov/medicaid/1915c/default.asp

Checkovich, T.J. and S. Stern (2002) "Shared Caregiving Responsibilities of Adult Children with Elderly Parents" Journal of Human Resources (Summer) 37(3): 441-478.

Chiappori, P.A. (1988) "Rational Household Labor Supply" Econometrica 56 (1):63-70.

Chiappori, P.A. (1992) "Collective Labor Supply and Welfare" Journal of Political Economy 100(3):437-467.

Crimmins, E.M., and D. Ingegneri (1990) "Interactions and Living Arrangements of Older Parents and their Children” Research on Aging 12:3-35.

Davis M.A., D.J. Moritz, J. Neuhaus, J.D. Barclay and L. Gee (1997) “Living Arrangements, Changes in Living Arrangements and Survival Among Community Dwelling Older Adults” American Journal of Public Health 87:371-77.

Dostie, B., P.T. Leger (2003) “The Living Arrangement Dynamics of Sick, Elderly Individuals” Paper presented at the 2004 ASSA annual meeting, San Diego, CA.

Dwyer, J.W. and R.T. Coward (1991) "A Multivariate Comparison of the Involvement of Adult Sons Versus Adult Daughters in the Care of Impaired Adults" Journal of Gerontology: Social Sciences 46:S259-269. 
Ellwood, D. and T. Kane (1990) "The American Way of Aging: An Event History Analysis" in D. Wise (ed.) Issues in the Economics of Aging. Chicago: University of Chicago Press: 121-147.

Engers, M. and S. Stern (2002) "Long-term Care and Family Bargaining" International Economic Review 43(1):1-44.

England, P. and N. Folbre (2003) "Contracting for Care," in M. Ferber and J. Nelson, eds., Ten Years Beyond Economic Man, Chicago: University of Chicago Press: 61-79.

Ettner, S.L. (1995) "The Impact of Parent Care on Female Labor Supply Decisions" Demography 32(1):63-80.

Ettner, S.L. (1996) “The Opportunity Costs of Elder Care” Journal of Human Resources 31(1):189-205.

Freedman, V.A. (1996) "Family Structure and the Risk of Nursing Home Admission" Journal of Gerontology: Social Sciences 51B:S61

Garber, A., and T. MaCurdy (1990) "Predicting Nursing Home Utilization Among High Risk Elderly” In Issues in the Economics of Aging. D. Wise (ed.) Chicago: University of Chicago Press: 173-204.

Gugl, E. (2004) "Joint vs. Individual Taxation and Intrafamily Distribution" University of Victoria Working Paper.

Hayashi, F. (1995) "Is the Japanese Extended Family Altruistically Linked? A Test Based on Engel Curves" Journal of Political Economy, 103(3), pages 661-74.

Heidemann, B. and S. Stern (1999) "Strategic Play Among Family Members When Making Long-Term Care Decisions" Journal of Economic Behavior and Organization 40:29-57.

Kalai, E. and M. Smorodinsky (1975) "Other Solutions to Nash's Bargaining Problem" Econometrica, 43(3):513-518.

Kemper, P. and L.E. Pezzin (1996) "The Effect of Public Provision of Home Care on Living and Care Arrangements: Evidence from the Channeling Experiment" In R. Eisen and F. Sloan, (eds.). Alternatives for Ensuring Long-Term Care. Amsterdam: Kluwer Press, pp.125-146.

Konrad, K., H. Kunemund, K. E. Lommerud, and J. R. Robledo (2002) "Geography of the Family" American Economic Review 92(4):981-998. 
Kotlikoff, L. and J. Morris (1990) "Why Don't the Elderly Live with Their Children? A New Look" in D. Wise (ed.) Issues in the Economics of Aging. Chicago: University of Chicago Press: 149-169.

Kreps, D.M. (1990). A Course in Microeconomic Theory. Princeton: Princeton University Press.

Lundberg, S. and R.A. Pollak (1993) "Separate Spheres Bargaining and the Marriage Market" Journal of Political Economy 101(6):988-1010.

Lundberg, S. and R.A. Pollak (1994) "Noncooperative Bargaining Models of Marriage" American Economic Review 84(2):132-137.

Lundberg, S. and R.A. Pollak (2003) "Efficiency in Marriage" Review of Economics of the Household 1(3):153-168.

Lundberg, S.J., R.A. Pollak, and T.J. Wales (1997) "Do Husbands and Wives Pool Their Resources? Evidence from the United Kingdom Child Benefit” Journal of Human Resources 32(3):463-480.

Manser, M. and M. Brown (1980) "Marriage and Household Decision Making" International Economic Review 21(1):31-44.

McElroy, M. and M.J. Horney (1981) "Nash-Bargained Household Decisions: Toward a Generalization of the Theory of Demand" International Economic Review 22(2):333-349.

McKelvey, R. and T. Palfrey (1992) "An Experimental Study of the Centipede Game," Econometrica 60(4): 803-836.

Moon, M. (1983) “The Role of the Family in the Economic Well-Bring of the Elderly” The Gerontologist 23(1):45-50.

Norton, E. (2000) “Long-Term Care,” in A. Culyer and J. Newhouse, eds. Handbook of Health Economics. Volume 1B. Handbooks in Economics, vol. 17. Amsterdam; New York and Oxford: Elsevier Science, North-Holland, 955-94.

Pezzin, L.E., R.A. Pollak, and B.S. Schone (2005a) "Bargaining Power and Intergenerational Coresidence: Adult Children and Their Disabled Elderly Parents"

Pezzin, L.E., R.A. Pollak, and B.S. Schone (2005b) "Long-Term Care of the Disabled Elderly: Do Children Increase Caregiving by Spouses?"

Pezzin, L.E., R.A. Pollak, and B.S. Schone (2005c) "Marital Disruption, Step Children, and Transfers to the Elderly" 
Pezzin, L.E. and B.S. Schone (1997) "The Allocation of Resources in Intergenerational Households: Adult Children and Their Elderly Parents" American Economic Review 87(2): 460-464.

Pezzin, L.E. and B.S. Schone (1999a) "Intergenerational Household Formation, Female Labor Supply, and Informal Caregiving: A Bargaining Approach" Journal of Human Resources 34(3):475-503.

Pezzin, L.E. and B.S. Schone (1999b) "Parental Marital Disruption and Intergenerational Transfers: An Analysis of Lone Elderly Parents and their Adult Children" Demography 36(3):287-298.

Pezzin, L.E. and B.S. Schone (2001) "Examining Motives for Intergenerational Transfers: A New Test Based on Siblings’ Behavior" Working paper, AHRQ, Rockville, MD.

Pezzin, L.E. and B.S. Schone (2002a) "Intergenerational Transfers of Time and Elderly Living Arrangements: A Bargaining Model of Family Resource Allocation Decisions" Working paper, AHRQ, Rockville, MD.

Pezzin, L.E. and B.S. Schone (2002b) "Exploring the Theoretical Foundations of Altruism: An Analysis of the Effects of Divorce and Remarriage on Intergenerational Living and Care Arrangements" in P.K. Chopra and B.N. Ghosh (eds.) Gender and Development. Wisdom House Press: England: 93-118.

Pollak, R.A. (1988) "Tied Transfers and Paternalistic Preferences" American Economic Review 78(2):240-244.

Pollak, R.A. (2003) "Gary Becker's Contributions to Family and Household Economics" Review of Economics of the Household 1(1-2):111-141.

Shubik, M. (1989) "Cooperative Games" In The New Palgrave, Game Theory, edited by J. Eatwell, M. Milgate, and P. Newman, New York: W.W. Norton, 103-107.

Spillman, B. and L.E. Pezzin (2000) "Potential and Active Family Caregivers: Changing Networks and the 'Sandwich' Generation” Milbank Quarterly 78(3):347-374.

Stern, S. (1993) "Two Dynamic Discrete Choice Estimation Problems and Simulation Method Solutions" Review of Economics and Statistics 96(4):695-102.

Stern, S. (1995) "Estimating Family Long-Term Care Decisions in the Presence of Endogenous Child Characteristics" Journal of Human Resources 30(3):551-580.

U.S. Census Bureau (2005) Statistical Abstract of the United States U.S. Department of Commerce, Washington, DC.

United Nations (2005) Living Arrangements of Older Persons Around the World Department of Economic and Social Affairs. Population Division. United Nations: New York, NY. 
Weiss, Y. and R. J. Willis (1985) "Children as Collective Goods in Divorce Settlements" Journal of Labor Economics 3(3): 268-292.

Wolf, D. and B. Soldo (1994) "Married Women's Allocation of Time to Employment and Care of Elderly Parents" Journal of Human Resources 29(4):1259-1276. 


\section{Figure 1: Children's Reaction Functions for Transfers}

Transfers from Child 2

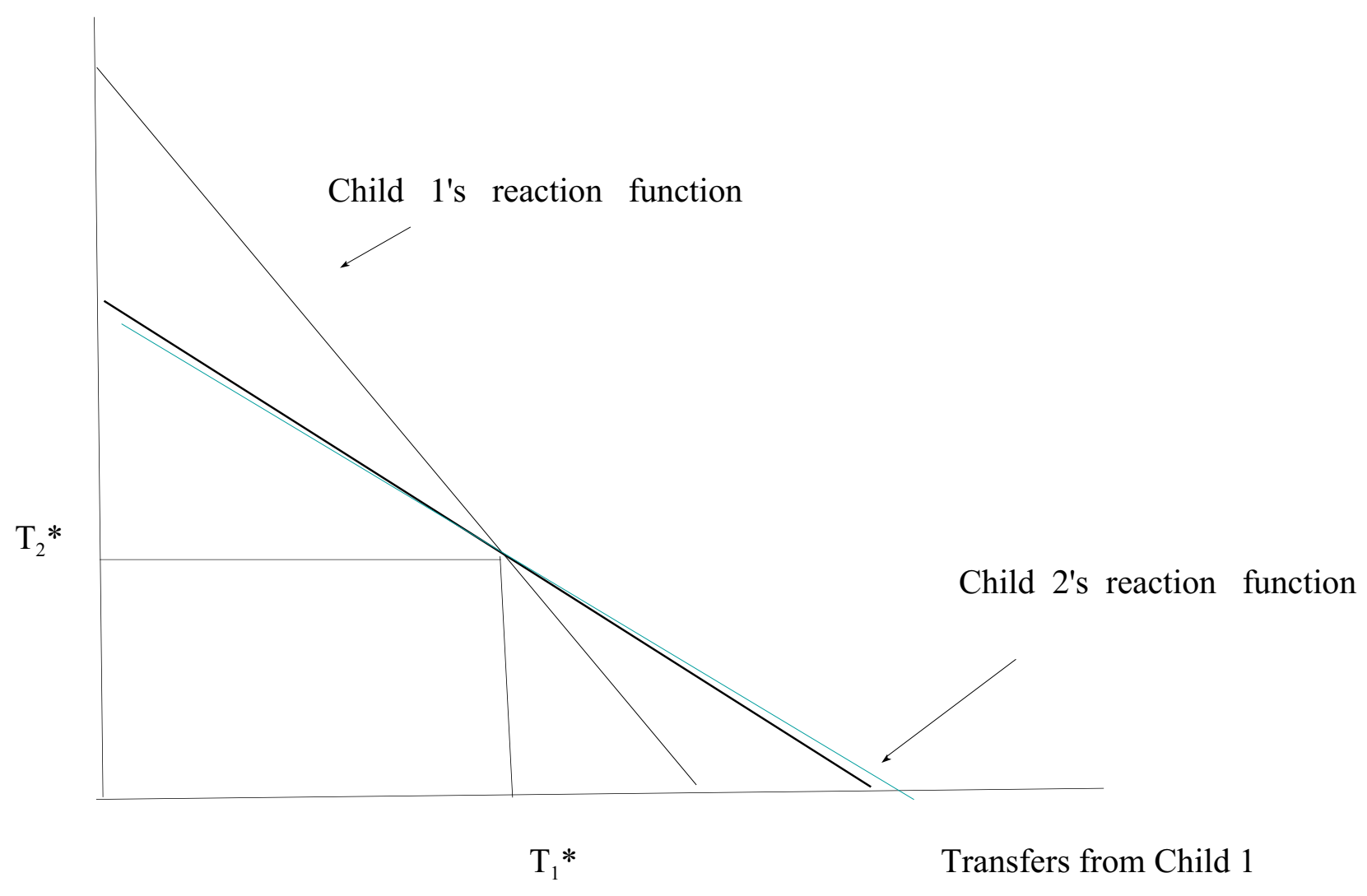


Figure 2: The Nash Bargaining Solution between the Children

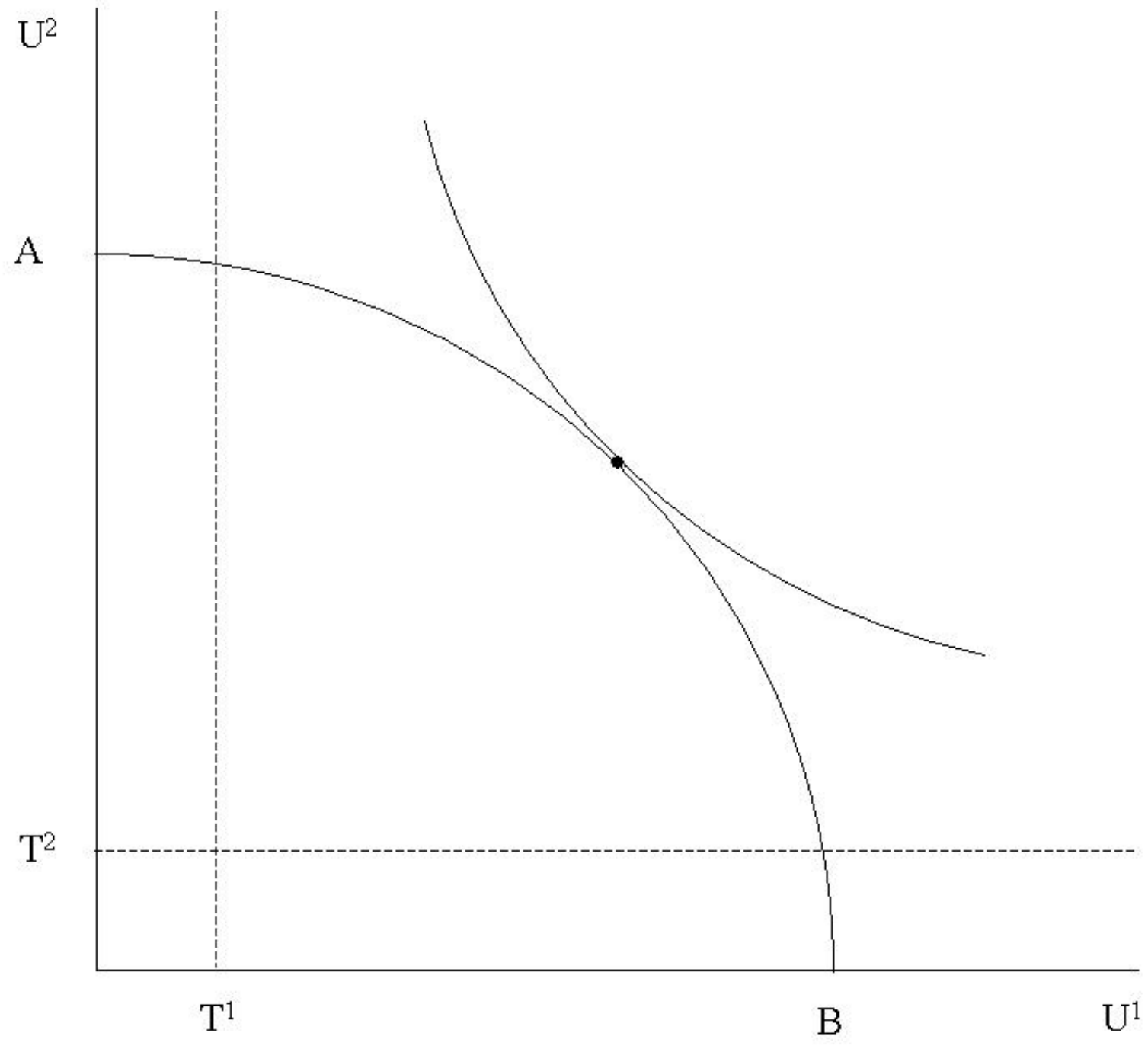

